\title{
A population profile of older adults with prescription encounters with nurse practitioners and family physicians in Ontario: a descriptive retrospective cohort study
}

\author{
Dana S. Edge RN PhD, Joan E. Tranmer RN PhD, Xuejiao Wei MSc, \\ Elizabeth G. VanDenKerkhof RN DrPH
}

Abstract

Background: Compared with patients in family physician practices, there is a poor understanding at a population level of patients in nurse practitioner practices. The study aim was to use Ontario administrative databases to identify the sociodemographic characteristics and comorbidities of patients aged 65 years and older who were prescribed medications by nurse practitioners and family physicians between 2000 and 2015.

Methods: This population-based descriptive retrospective cohort study included patients 65 years of age and older with Ontario Health Insurance Plan eligibility and at least 1 prescription encounter with a nurse practitioner or family physician during the study period. Prescription identification of patients permitted their characterization by age, sex, geographical location, rurality, neighbourhood income and comorbidities. Patients were categorized into 3 provider groups on the basis of the percentage of prescription encounters with nurse practitioners versus family physicians.

Results: In 2015, patients in the study cohort with prescriptions by nurse practitioners ( $n=25220)$ were younger than those with prescriptions by family physicians $(40.3 \%$ were aged $65-69 \mathrm{yr}$ ) and they were more likely to be residents of low-income neighbourhoods (44.0\% were in the lowest 2 neighbourhood income quintiles) and to be living outside of central Ontario. In contrast, patients who received prescriptions from family physicians $(n=1952904)$ tended to be older ( $26.8 \%$ were aged $\geq 80 \mathrm{yr})$, to have higher incomes (21.1\% were in the highest neighbourhood income quintile) and to live in urban areas (86.5\%). Mean Elixhauser Comorbidity Index scores were consistently lower among patients cared for by nurse practitioners than among those predominantly seen by family physicians (1.30 v. 2.04). The most prevalent conditions were hypertension and diabetes, regardless of provider.

Interpretation: The patient characteristic with the highest variability between providers was geographic residence in the province. Elucidating patterns of care is critical for primary care policy and our results provide baseline data for future health care planning.

\begin{abstract}
T ntegrated, patient-centred care is a central tenet of Ontario's primary health care system. ${ }^{1}$ One mechanism that has been proposed to achieve integrated, patientcentred care is the introduction of nurse practitioners (NPs) into various primary health care models. ${ }^{1-4}$ Educated in graduate schools and granted autonomous scope of practice, Ontario NPs can assess, diagnose and manage patient conditions that present in primary, long-term and tertiary care settings. ${ }^{5,6}$ In 2017, registered NPs in Ontario numbered 3083 with $75 \%$ in primary care, ${ }^{7}$ and they constituted over $50 \%$ of those licensed in Canada. ${ }^{8}$ Most Ontario primary care NPs are salaried and work in interdisciplinary team environments (e.g., family health teams, community health centres). They may have an Ontario Health Insurance Plan (OHIP) provider number for ordering referrals, labwork and specified diagnostic imaging tests, but they do not bill the province of
\end{abstract}

Ontario for direct services. ${ }^{9}$ Twenty-five NP-led clinics have been established in Ontario, with 9 located in communities with populations under $10000 .{ }^{10}$ Slightly more than $4 \%$ of Ontario NPs were employed in NP-led clinics in 2017, whereas nearly $19 \%$ and $16 \%$ worked in family health teams and community health centres, respectively. ${ }^{7,11}$ Prospective patients wishing to access a NP are directed to the same provincial website used to request a family physician (FP).

\section{Competing interests: None declared.}

This article has been peer reviewed.

Correspondence to: Dana Edge, dana.edge@queensu.ca CMAJ Open 2019. DOI:10.9778/cmajo.20190007 
Numerous studies over the past 40 years have ascertained the safety of NP practice, most often comparing equivalencies between NPs and their physician counterparts. ${ }^{12-17}$ Recent effectiveness studies have examined NP practice in primary care, ${ }^{18-20}$ tertiary care ${ }^{21-23}$ and specialized settings, including the care of rural, frail elderly clients, ${ }^{24}$ clients with diabetes ${ }^{25}$ and clients with dementia. ${ }^{26}$ Although there is a large body of knowledge on the safety, effectiveness and role development of NP practice, ${ }^{27-33}$ minimal information is available regarding their patients, a gap we identified in our previous work. ${ }^{34}$ Recent evidence regarding NP practice in Ontario is emerging. In 2012, the Centre for Rural and Northern Health Research in Sudbury, Ontario, conducted a comprehensive survey and reported that the majority of Ontario NPs' clientele were adults; $42 \%$ of clients were adults younger than 65 years and $32 \%$ were seniors. ${ }^{35}$ Although the sampling frame included all practising NPs, only $48 \%(n=693)$ responded. Using data from the Ontario Nurse Practitioner Access Reporting pilot project, ${ }^{36}$ Heale and colleagues recently reported NP encounter data from 34 family health teams in 2014/15, linked with data from other provincial databases. ${ }^{37}$ They found that NPs saw a wide range of patients with acute (22\%) and chronic (20\%) conditions; hypertension was the most common comorbidity, followed by asthma. The authors acknowledged that only $2.9 \%$ of all NPs working in primary care in Ontario were represented. Despite these advances, the population-level characteristics of patients who have NP encounters remain poorly understood, including geographic variation and demographic trends. To address this gap, we used Ontario administrative health databases to identify and categorize the clinical and sociodemographic profile of patients aged 65 years and older who had prescription encounters with Ontario NPs and family physicians (FPs) between 2000 and 2015 .

\section{Methods}

\section{Study design and data sources}

This was a population-based, retrospective cohort study that described the characteristics of patients aged 65 years or older who received prescriptions from NPs and FPs in Ontario, Canada. Data linkage and analysis was undertaken by the third author (X.W.), who has institutional clearance to access provincial administrative databases at ICES. The Corporate Provider Database, ${ }^{38}$ a provider registry derived from the lists of health care professionals registered with each respective professional licensing college, is maintained by the Ontario Ministry of Health and Long-Term Care and updated quarterly. It was used to obtain practice information as well as a prescriber ID for NPs and physicians with an OHIP billing number; and the ICES Physician Database was used to identify a physician's main specialty. The prescriber IDs of the identified providers were used to link to prescriptions dispensed to older adults ( $\geq 65 \mathrm{yr}$ ) covered under the Ontario Drug Benefit program, which contains detailed information on all outpatient prescriptions covered by the provincial drug formulary. As Ontario NPs do not enrol or roster patients, it is impossible to link patient health card numbers with NP encounters; ${ }^{37}$ therefore, the prescriber ID in the Ontario Drug Benefit database provides a restricted mechanism to evaluate NP practice using seniors' prescription care. Linkage to the Registered Persons Database provided us with basic demographic information for all residents who had ever received an OHIP number, and linkage to the Client Agency Program Enrolment database provided information on family health teams. These databases were linked using unique encoded identifiers (Figure 1, Appendix 1, available at www.cmajopen.ca/content/7/2/E323/supp1/DC1) and analyzed at ICES.

\section{Study population}

The study included Ontario residents who were aged 65 years or older with a valid ICES unique identifier, alive and eligible for health care with at least 1 prescription dispensed by a NP or FP in each year between Jan. 1, 2000, and Dec. 31, 2015. Cohort ascertainment was limited to the end of 2015 on the basis of database completeness. Each prescription dispensation date with the same provider was counted as 1 encounter. Total numbers of encounters with NPs and FPs were calculated for each patient in each study year. Patients within each study year were assigned to 1 of 3 care provider groups (NP, FP and shared care group) on the basis of the percentage of his or her prescription encounters with NPs versus FPs. Within each study year, patients who had more than $70 \%$ of their encounters with NPs were attributed to the NP care group, and patients who had more than $70 \%$ of their encounters with FPs were attributed to the FP care group. Patients who had less than $70 \%$ of their encounters with either group were attributed to the shared care group. The $70 \%$ cut-off was determined on the basis of the distribution of encounters in each study year and the existing Ontario literature..$^{30,37}$

\section{Patient characteristics}

Patient characteristics including age, sex, geographic region of residence, neighbourhood income quintile, rurality of residence, marginalization index and comorbidity were described by provider care groups within each study year. Age was defined at first dispensation date in each year. Geographic region of residence at the first dispensation date was described at the level of the 14 Local Health Integration Networks (LHINs) in Ontario. ${ }^{39}$ Neighbourhood income quintiles were based on the average household income in a neighbourhood census tract and ranked into 5 ascending categories, with the lowest quintile representing the least affluent neighbourhoods. ${ }^{40}$ Rurality was measured using the Rurality Index for Ontario 2008, with a score less than 40 being urban. ${ }^{41}$ The Ontario Marginalization Index is a geographically based index developed to quantify the degree of marginalization occurring across the province, with a quintile of 5 reflecting the greatest magnitude of marginalization. ${ }^{42}$ It comprises 4 major dimensions thought to underlie the construct of marginalization: residential instability, material deprivation, dependency and ethnic concentration. Comorbidity was 

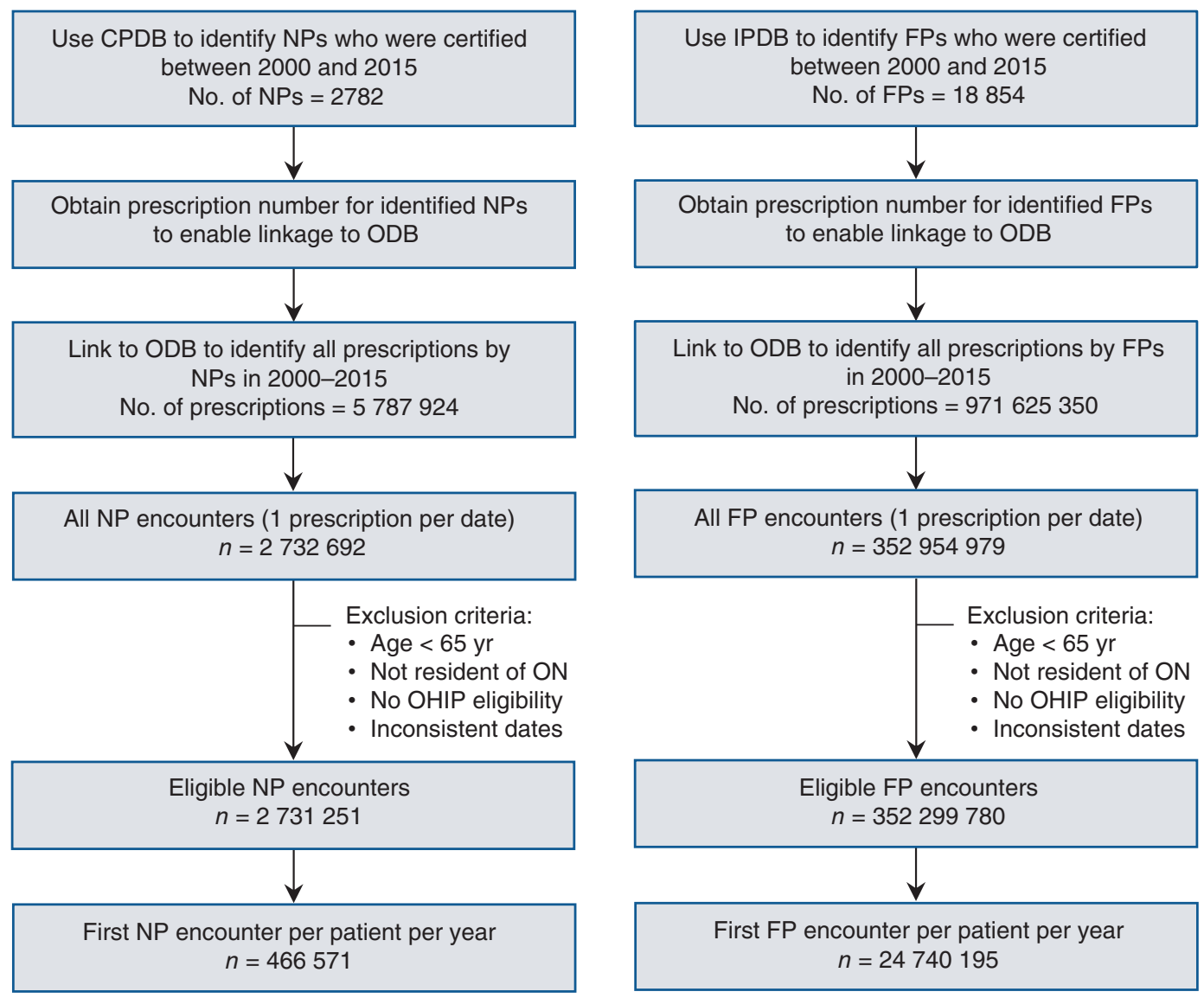

Figure 1: Flow diagram of cohort identification. Each dispensing date is counted as 1 encounter (i.e., multiple prescriptions on the same date are counted as 1 encounter). The exclusion criterion "inconsistent dates" represents situations in which the death date came before the dispensing date. Note: $\mathrm{CPDB}=$ Corporate Provider Database, FP = family physician, IPDB = ICES Physician Database, NP = nurse practitioner, ODB = Ontario Drug Benefit database, OHIP = Ontario Health Insurance Plan, ON = Ontario.

classified using the Elixhauser Comorbidity Index, a measurement score that includes diagnosis codes based on the International Classification of Diseases of 30 coexisting conditions found in the hospital abstracts data (the Discharge Abstract Database maintained by the Canadian Institute for Health Information) and in the medical services (OHIP) data within the 2 years preceding the first dispensation date. ${ }^{43,44}$ Type of practice was dichotomized by enrolment in family health teams, as NP-led clinics and community health centres are not captured in provincial databases.

\section{Analysis}

Patients in each of the provider groups were described per year with respect to their number of encounters and sociodemographic characteristics. To examine geographic variation in the pattern of encounters, we mapped the proportion of patients cared for by each provider group within each of Ontario's 14 health regions by study year. The proportions of patients with each Elixhauser comorbid condition within each provider group per study year were generated and ranked to identify the 5 most common comorbid conditions by provider group. All analyses were performed using SAS version 9.4 (SAS Institute).

\section{Ethics approval}

The study was approved by the Health Sciences and Affiliated Teaching Hospitals Research Ethics Board of Queen's University in Kingston.

\section{Results}

Over the 15-year study period, the total number of NPs who prescribed to patients aged 65 years and older increased by 2439 from 340 in 2000, whereas an additional 3514 FPs prescribed to older adults from the baseline of $10201 \mathrm{FPs}$. The numbers of providers who prescribed to older adults over the 
study period are presented in Table 1 . Both provider groups experienced an increase in the provider-to-patient ratio over time. In 2010, over $99 \%$ of patients were assigned to FP care ( $n=1624783)$; by 2015, the percentage of patients who received more than $70 \%$ of their prescriptions from FPs had dropped to $97 \%(n=1952904)$, with the percentages of patients assigned to shared care $(n=28428)$ and NP care $(n=$ 25 220) at slightly over $1 \%$ each (Table 2).

\section{Clinical and sociodemographic profile}

In 2010, $40.3 \%$ of older adults receiving prescriptions from NPs were between the ages of 65 and 69 years, whereas $35.2 \%$ of those assigned to shared care and $30.4 \%$ of those assigned to FP care were in this age group (Table 2). In 2015, patients aged 85 years old and older represented a greater percentage $(16.5 \%)$ of the patients who had prescription encounters in the shared care group than they had in 2005 or 2010. Female patients consistently were slightly more likely than male patients to receive prescriptions either from NPs or in the shared care group. During the study period, proportionately more older patients living in lowincome neighbourhoods received medications from NPs or in the shared care group than FPs; however, the mean marginalization index was intermediate for all patients, regardless of provider group, across the study time frame. Half $(50.8 \%)$ of the patients aged 65 years and older who received prescriptions in the shared care group in 2005 lived in rural areas, and $29.7 \%$ of those who received prescriptions from a NP were rural residents. By 2010 this had changed, as
$47.4 \%$ of older patients assigned to NPs were rural residents compared with $41.1 \%$ of their counterparts assigned to shared care. These proportions dropped in 2015: the percentage of prescriptions to rural residents was $37.4 \%$ in the NP group and $28.0 \%$ in the shared care group. The proportion of rural patients who received prescriptions predominately from FPs was consistently around 14\% throughout the study period. In summary, in 2015, older patients who received prescriptions from NPs were typically between 65 and 69 years of age $(40.3 \%)$, women $(59.2 \%)$, residents of neighbourhoods in the lowest 2 income quintiles $(44.0 \%)$ and residents of rural areas (37.4\%) (Table 2).

The LHIN geographic distributions of older adults by provider group in 2005 and 2015 are depicted in Figure 2. In 2005 , the total numbers of NP prescription encounters were small, but of the patients who had these encounters, the highest proportions (depicted in red) resided in the regions of the South West LHIN (37.4\%) and the North East LHIN (14.2\%). By 2015, the proportion of prescriptions by NPs for older patients in the South West LHIN had dropped $(11.5 \%)$, and the highest proportion was found in the North East LHIN (21.3\%). For FPs in 2005, the greatest proportions of prescription encounters for older patients were in the Hamilton Niagara Haldimand Brant LHIN area $(12.8 \%)$, followed by the Central East LHIN (11.9\%) and Central LHIN (11.4\%) regions. The distribution of older patient encounters by FPs did not change appreciably between 2005 and 2015. The distribution of older patients in the shared care group in 2005 was highest

Table 1: Numbers of nurse practitioners and family physicians who prescribed to older adults in Ontario and characteristics of their practices, 2000-2015

\begin{tabular}{|c|c|c|c|c|c|c|}
\hline 2000 & 340 & 240 & 0.7 & 10201 & 1222981 & 119.9 \\
\hline 2001 & 389 & 666 & 1.7 & 10284 & 1246747 & 121.2 \\
\hline 2002 & 429 & 913 & 2.1 & 10319 & 1269956 & 123.1 \\
\hline 2003 & 516 & 894 & 1.7 & 10511 & 1297025 & 123.4 \\
\hline 2005 & 626 & 2304 & 3.7 & 10764 & 1401119 & 130.2 \\
\hline 2006 & 701 & 3741 & 5.3 & 10818 & 1444228 & 133.5 \\
\hline 2007 & 862 & 6464 & 7.5 & 10964 & 1489519 & 135.9 \\
\hline 2008 & 1023 & 12362 & 12.1 & 11055 & 1536712 & 139.0 \\
\hline 2009 & 1259 & 17988 & 14.3 & 11379 & 1584402 & 139.2 \\
\hline 2013 & 2151 & 80450 & 37.4 & 12603 & 1866449 & 148.1 \\
\hline 2014 & 2438 & 97549 & 40.0 & 13301 & 1930461 & 145.1 \\
\hline 2015 & 2779 & 119679 & 43.1 & 13715 & 1991077 & 145.2 \\
\hline
\end{tabular}


Table 2: Characteristics of older patients, by predominant provider group in 2005, 2010 and 2015

\begin{tabular}{|c|c|c|c|c|c|c|c|c|c|}
\hline \multirow[b]{3}{*}{ Characteristic } & \multicolumn{9}{|c|}{ No. $(\%)$ of patients* } \\
\hline & \multicolumn{3}{|c|}{2005} & \multicolumn{3}{|c|}{2010} & \multicolumn{3}{|c|}{2015} \\
\hline & $\begin{array}{c}\text { NP } \\
n=155\end{array}$ & $\begin{array}{c}\text { FP } \\
n=1400846\end{array}$ & $\begin{array}{l}\text { Shared } \\
n=262\end{array}$ & $\begin{array}{c}\text { NP } \\
n=3849\end{array}$ & $\begin{array}{c}\text { FP } \\
n=1624783\end{array}$ & $\begin{array}{c}\text { Shared } \\
n=5611\end{array}$ & $\begin{array}{c}\text { NP } \\
n=25220\end{array}$ & $\begin{array}{c}\text { FP } \\
n=1952904\end{array}$ & $\begin{array}{c}\text { Shared } \\
n=28428\end{array}$ \\
\hline \multicolumn{10}{|l|}{ Age, yr } \\
\hline $65-69$ & $47(30.3)$ & $403744(28.8)$ & $91(34.7)$ & $1566(40.7)$ & $493855(30.4)$ & 1975 (35.2) & $10153(40.3)$ & $650183(33.3)$ & 9009 (31.7) \\
\hline 70-74 & $30(19.4)$ & $337404(24.1)$ & $48(18.3)$ & $938(24.4)$ & 365745 (22.5) & $1218(21.7)$ & $6048(24.0)$ & $436491(22.4)$ & $6081(21.4)$ \\
\hline $75-79$ & $27(17.4)$ & 289357 (20.7) & $51(19.5)$ & $641(16.7)$ & 312661 (19.2) & $1036(18.5)$ & 3919 (15.5) & $341012(17.5)$ & $4682(16.5)$ \\
\hline $80-84$ & $30(19.4)$ & $213387(15.2)$ & $42(16.0)$ & $410(10.7)$ & $238200(14.7)$ & $731(13.0)$ & $2643(10.5)$ & 260649 (13.3) & 3957 (13.9) \\
\hline$\geq 85$ & $21(13.5)$ & $156954(11.2)$ & $30(11.5)$ & $294(7.6)$ & $214322(13.2)$ & $651(11.6)$ & $2457(9.7)$ & 264569 (13.5) & 4699 (16.5) \\
\hline \multicolumn{10}{|l|}{ Sex } \\
\hline Female & $94(60.6)$ & 811395 (57.9) & $174(66.4)$ & $2378(61.8)$ & $920928(56.7)$ & $3500(62.4)$ & 14941 (59.2) & 1083923 & $16944(59.6)$ \\
\hline Male & $61(39.4)$ & $589451(42.1)$ & $88(33.6)$ & $171(38.2)$ & 703855 (43.3) & $2111(37.6)$ & $10278(40.8)$ & $868981(44.5)$ & $11484(40.4)$ \\
\hline \multicolumn{10}{|c|}{ Neighbourhood income quintile } \\
\hline 1 (lowest) & $45(29.0)$ & $289167(20.6)$ & $63(24.0)$ & $883(22.9)$ & $307740(18.9)$ & $1382(24.6)$ & $5783(22.9)$ & $347033(17.8)$ & $6347(22.3)$ \\
\hline 2 & $19(12.3)$ & 297894 (21.3) & $67(25.6)$ & $831(21.6)$ & $332835(20.5)$ & $1154(20.6)$ & $5312(21.1)$ & $387649(19.8)$ & 5595 (19.7) \\
\hline 3 & $12(7.7)$ & $272929(19.5)$ & $43(16.4)$ & $725(18.8)$ & $321089(19.8)$ & $992(17.7)$ & 4935 (19.6) & $387553(19.8)$ & $5530(19.5)$ \\
\hline 4 & $52(33.5)$ & $267444(19.1)$ & $38(14.5)$ & $717(18.6)$ & $327659(20.2)$ & $1097(19.6)$ & $4651(18.4)$ & $412065(21.1)$ & 5459 (19.2) \\
\hline 5 (highest) & $26(16.8)$ & $269312(19.2)$ & $51(19.5)$ & $646(16.8)$ & $329804(20.3)$ & $944(16.8)$ & $4354(17.3)$ & $411648(21.1)$ & $5292(18.6)$ \\
\hline \multicolumn{10}{|l|}{ Rurality index } \\
\hline Urban $(<40)$ & $108(69.7)$ & $1196667(85.4)$ & $129(49.2)$ & $2023(52.6)$ & $1396072(85.9)$ & $3286(58.6)$ & $15776(62.6)$ & $1689397(86.5)$ & $20460(72.0)$ \\
\hline Rural $(\geq 40)$ & $46(29.7)$ & $203693(14.5)$ & $133(50.8)$ & $1826(47.4)$ & $228688(14.1)$ & $2325(41.4)$ & $9443(37.4)$ & $263469(13.5)$ & $7966(28.0)$ \\
\hline \multicolumn{10}{|c|}{ Ontario Marginalization Index } \\
\hline Mean \pm SD & $3.14 \pm 0.71$ & $3.22 \pm 0.79$ & $3.17 \pm 0.74$ & $3.12 \pm 0.70$ & $3.16 \pm 0.79$ & $3.15 \pm 0.75$ & $3.12 \pm 0.73$ & $3.11 \pm 0.79$ & $3.13 \pm 0.76$ \\
\hline Median (IQR) & $3(3-4)$ & $3(3-4)$ & $3(3-4)$ & $3(3-4)$ & $3(3-4)$ & $3(3-4)$ & $3(3-4)$ & $3(3-4)$ & $3(3-4)$ \\
\hline \multicolumn{10}{|c|}{ LHIN, $† \%$ of patients } \\
\hline 1 & 7.1 & 5.8 & 11.8 & 7.8 & 5.6 & 7.5 & 7.6 & 5.4 & 5.8 \\
\hline 2 & 37.4 & 8.4 & 11.1 & 13.0 & 8.1 & 11.9 & 11.5 & 7.9 & 10.1 \\
\hline 3 & 6.5 & 5.0 & 5.7 & 4.8 & 5.0 & 4.8 & 4.6 & 5.1 & 5.9 \\
\hline 4 & 7.1 & 12.8 & 9.9 & 5.7 & 12.5 & 9.9 & 6.8 & 12.1 & 12.1 \\
\hline 5 & 2.6 & 4.1 & 1.1 & 0.5 & 4.7 & 0.6 & 1.0 & 5.3 & 2.3 \\
\hline 6 & 0.0 & 6.6 & 0.4 & 0.9 & 6.9 & 1.7 & 1.5 & 7.4 & 3.3 \\
\hline 7 & 1.3 & 8.4 & 0.8 & 1.0 & 7.8 & 1.0 & 2.2 & 7.5 & 2.6 \\
\hline 8 & 0.6 & 11.4 & 3.1 & 1.8 & 11.8 & 2.4 & 2.8 & 12.5 & 3.6 \\
\hline 9 & 4.5 & 11.9 & 13.4 & 12.3 & 11.9 & 8.6 & 11.8 & 12.0 & 9.6 \\
\hline 10 & 5.8 & 5.0 & 8.4 & 12.0 & 4.9 & 13.0 & 9.6 & 4.7 & 10.2 \\
\hline 11 & 7.7 & 9.0 & 6.5 & 6.2 & 9.3 & 6.6 & 6.4 & 9.6 & 6.0 \\
\hline 12 & 3.2 & 3.9 & 4.2 & 4.3 & 4.0 & 4.7 & 6.0 & 4.0 & 7.5 \\
\hline 13 & 14.2 & 5.8 & 23.3 & 25.6 & 5.4 & 22.7 & 21.3 & 4.9 & 13.6 \\
\hline 14 & 1.9 & 2.0 & 0.4 & 4.1 & 1.9 & 4.5 & 6.9 & 1.7 & 7.5 \\
\hline \multicolumn{10}{|l|}{ FHT } \\
\hline Yes & $0(0.0)$ & $651(0.0)$ & $0(0.0)$ & 1765 (45.9) & $269436(16.6)$ & $2423(43.2)$ & 10918 (43.3) & $458358(23.5)$ & 13251 (46.6) \\
\hline No & $155(100)$ & $1400195(100)$ & $262(100)$ & $2084(54.1)$ & $1355347(83.4)$ & $3188(56.8)$ & $14302(56.7)$ & $1494546(76.5)$ & $15177(53.4)$ \\
\hline \multicolumn{10}{|l|}{ In LTC } \\
\hline Yes & $51(32.9)$ & $68862(4.9)$ & $22(8.4)$ & $15(0.4)$ & $74303(4.6)$ & $145(2.6)$ & $183(0.7)$ & 73227 (3.7) & $2019(7.1)$ \\
\hline No & $104(67.1)$ & 1331984 (95.1) & $240(91.6)$ & $3834(99.6)$ & $1550480(95.4)$ & $5466(97.4)$ & 25037 (99.3) & $1879677(96.3)$ & 26409 (92.9) \\
\hline
\end{tabular}



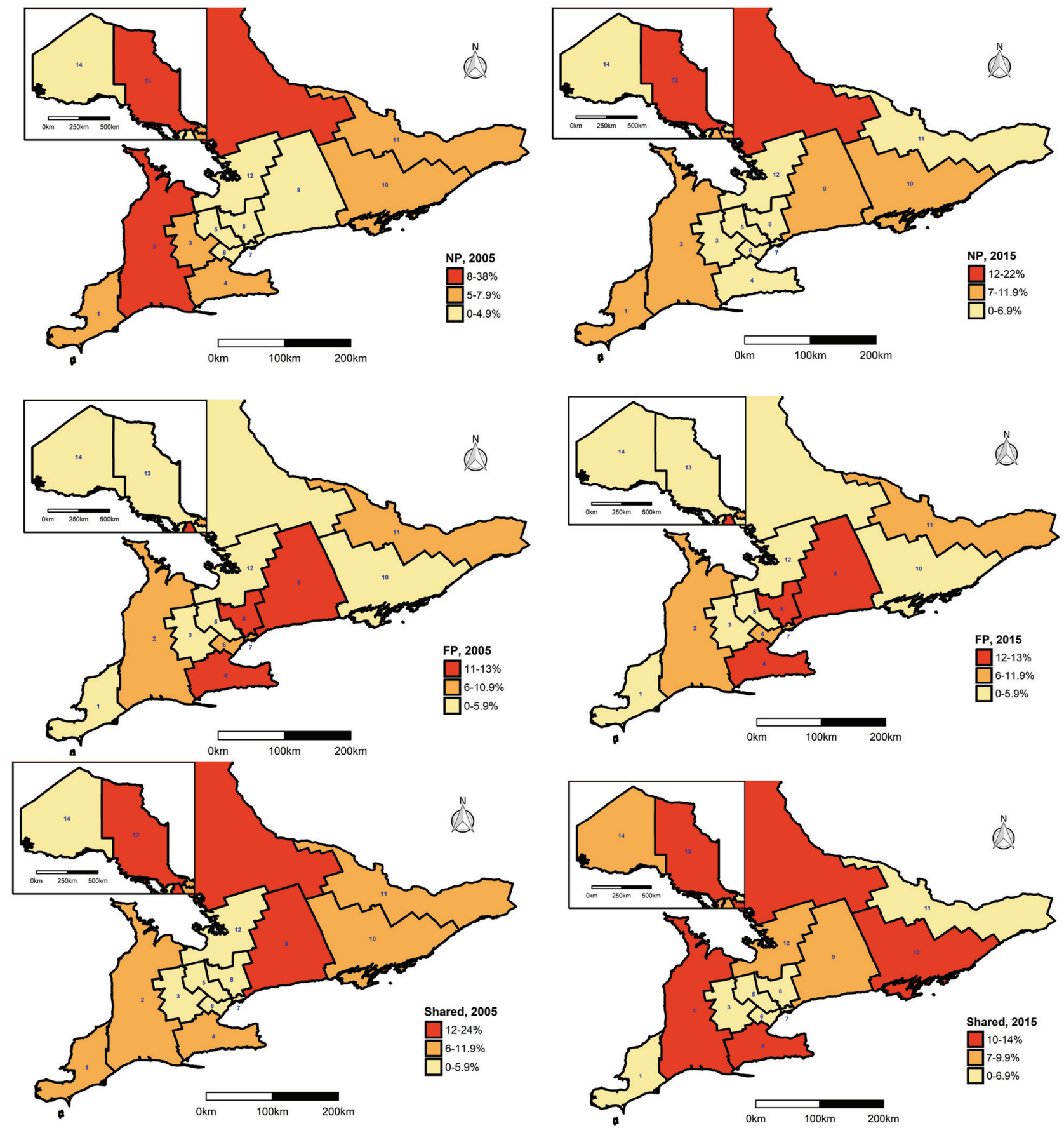

Figure 2: Proportion of prescription encounters for older patients in Local Health Integration Networks by provider group in 2005 and 2015. Maps were created by Paul Nguyen, ICES Queen's, using $R$ statistical software. Note: FP = family physician, NP = nurse practitioner, Shared = shared care practice.

in the North East LHIN (23.3\%) and in the Central East LHIN regions (13.4\%). In 2015, older adult encounters in the shared care group were highest in the following LHINs: North East (13.6\%), Hamilton Niagara Haldimand Brant $(12.1 \%)$, South East $(10.2 \%)$ and South West $(10.1 \%)$ (Table 2).
The mean number of prescription encounters per patient for FPs rose slightly over the study period (Figure 3). After the establishment of family health teams in 2005, the mean number of prescription encounters per patient for NPs and in shared care increased. In shared care, the mean number of encounters per patient was similar to that for FPs by 2015 . 


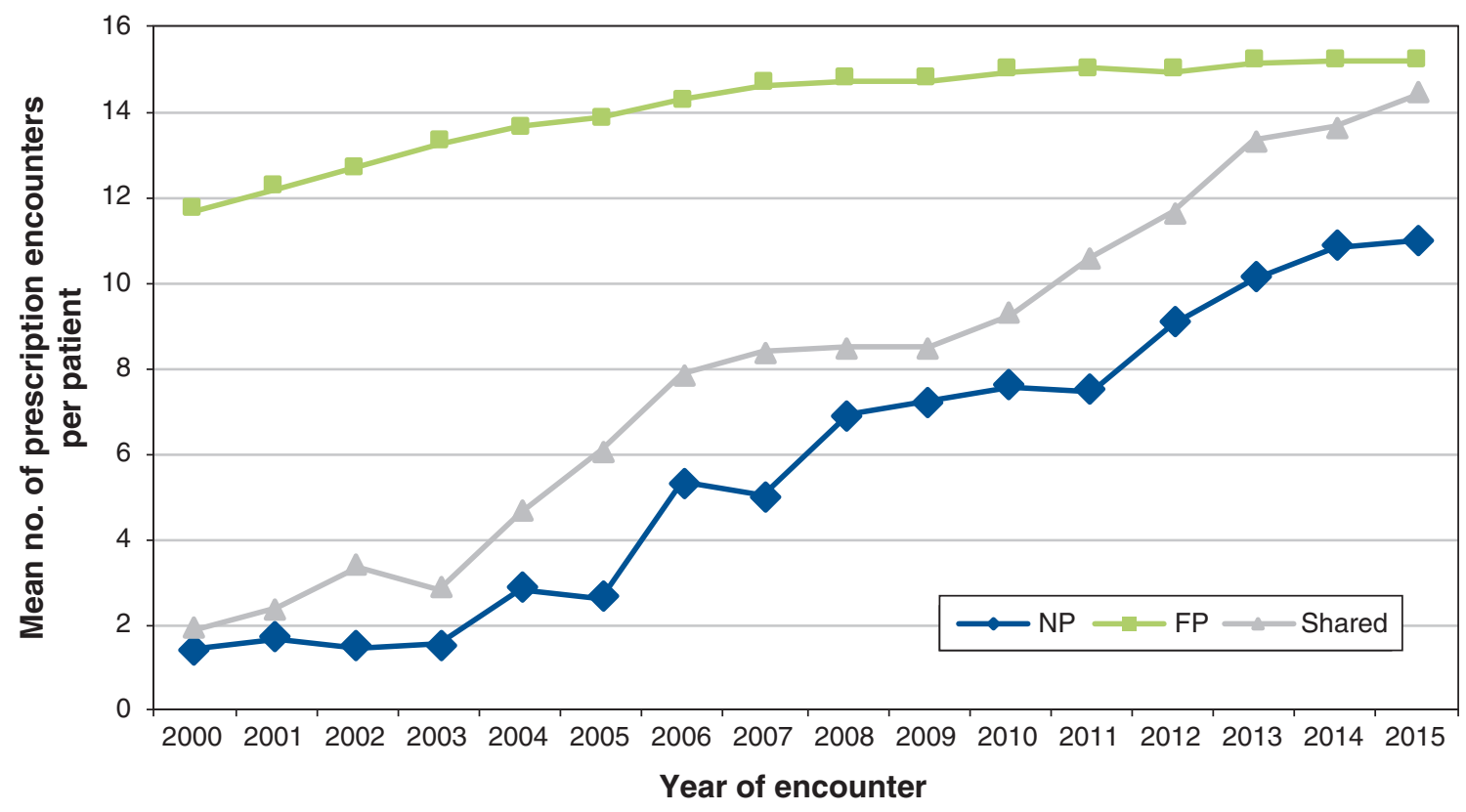

Figure 3: Mean number of prescription encounters per patient per year, by provider group, 2000-2015. Note: FP = family physician, NP = nurse practitioner, Shared $=$ shared care practice.

The mean number of NP prescription encounters per patient increased from 1.4 to 10.9 between 2000 and 2015. Proportionately, more patients with prescriptions in the NP group $(43.3 \%)$ and in the shared care group (46.6\%) were enrolled in family health teams compared with those in the FP group $(23.5 \%)$ in 2015 (Table 2).

Uncomplicated hypertension was the most common comorbidity of older patients from 2000 to 2015, regardless of provider group, followed by diabetes mellitus (data not shown). After 2005, patients in long-term care constituted less than $10 \%$ of the total cohort; they represented $0.7 \%$ of patients who received prescriptions from NPs (Table 2). The mean Elixhauser Comorbidity Index scores for patients who primarily had NP prescription encounters in 2015 were lower than those for patients with prescriptions from FPs $(1.30 \mathrm{v}$. 2.04) (Figure 4). Conversely, but not unexpectedly, the comorbidity index of patients who had shared care consistently increased, and by 2015 it was similar to that of patients seen predominately by FPs.

\section{Interpretation}

During the 15-year study period, NP prescription encounters with Ontario residents aged 65 years and older increased; the low mean number of patient prescription encounters by NPs in the early 2000s partially reflects the restrictive provincial formulary list in place until 2011. ${ }^{34}$ Overall, there were higher proportions of patients with NP prescription encounters within shared, interdisciplinary care. Two previous Ontario studies that classified primary care encounters also reported higher proportions of shared care in community health centres $^{30}(18 \%)$ and in family health teams ${ }^{37}$ (nearly $\left.7 \%\right)$, compared with our finding of slightly more than $1 \%$ in 2015 . This is not unexpected, as our study incorporated all practice types, was restricted to patients 65 years of age and older and only captured prescription encounters. Similar to our findings, studies in the United States found that patients cared for by NPs were slightly more likely to be female ${ }^{45-48}$ and to reside in rural or underserviced areas..$^{25,45-48}$ Contrary to the findings of studies in Ontario community health centres ${ }^{30}$ and the US ${ }^{46}$ that reported that higher proportions of patients of all ages cared for by NPs were marginalized than those cared for by family physicians, we did not find variation in the marginalization index of older adults across provider groups.

The patients who primarily received prescriptions from NPs had relatively low comorbidity index scores, possibly related to their younger age. The comorbidity index of patients with shared prescription care gradually rose over time to approximate the scores of patients seen primarily by FPs, suggesting that shared care allows complementary care for older patients with complex health care needs. Comparable comorbidity findings for older adults have been reported in the US. In a longitudinal study of Medicare data from 2007 to 2010, patients with diabetes receiving care from NPs had a significantly lower Elixhauser Comorbidity Index score $(p<$ 0.001 ) than those cared for by generalist physicians. ${ }^{46}$ Similarly, Medicare patients cared for by NPs in 2008 had a slightly lower Elixhauser score $(p<0.05)$ than patients cared 


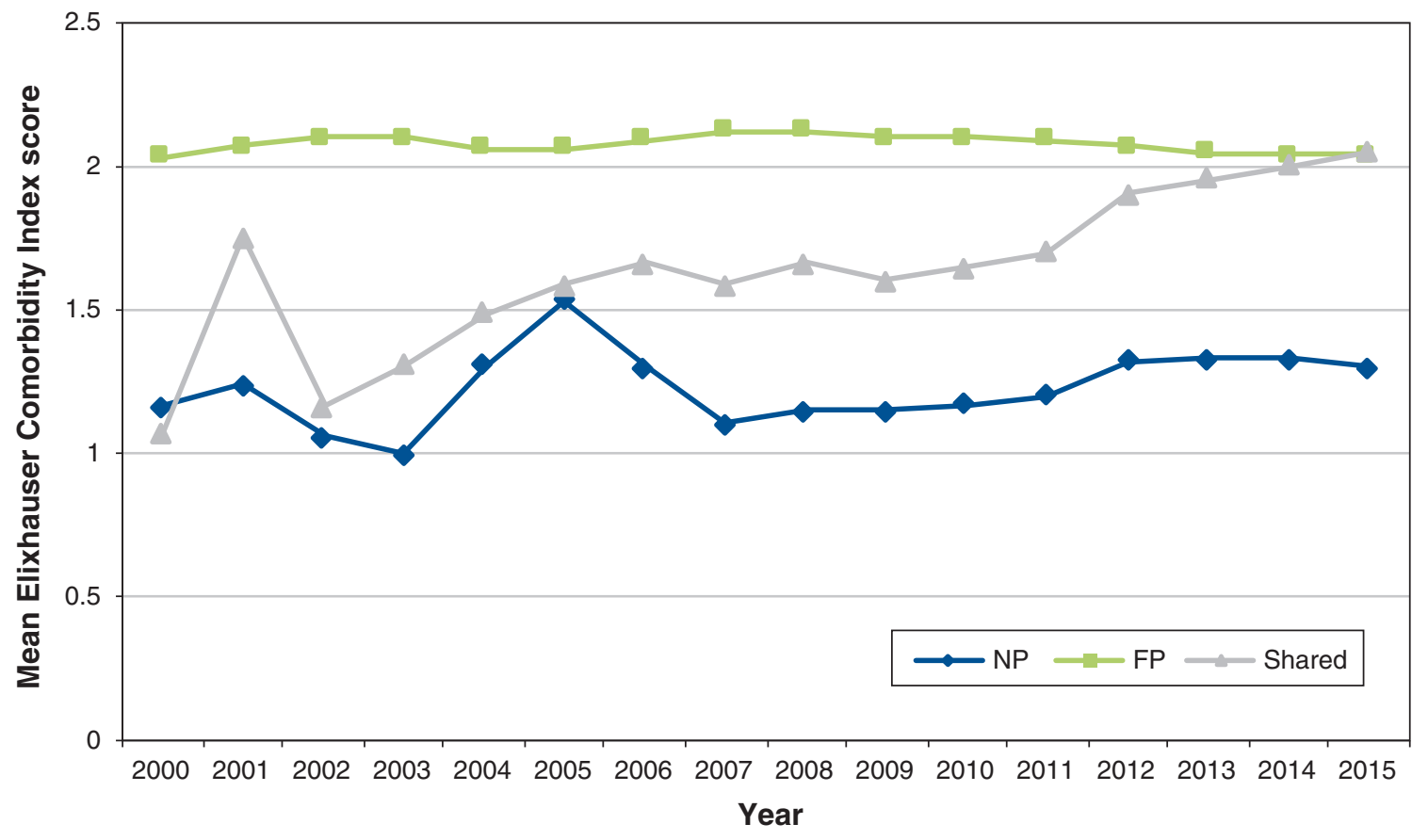

Figure 4: Mean Elixhauser Comorbidity Index score per year, by provider group, 2000-2015. Note: FP = family physician, NP = nurse practitioner, Shared $=$ shared care practice .

for by physicians. ${ }^{25}$ Finally, our findings parallel comorbidity gradients found in the Ontario Nurse Practitioner Access Reporting data, with the highest comorbidities among patients in the FP group, intermediate comorbidities for those in shared practice and the lowest ones among patients receiving care from NPs. ${ }^{37}$

NP prescription encounters were consistently highest in the remote northeast region of Ontario, which has the greatest number of NP-led clinics (6) in the province. ${ }^{10}$ The geographic variation found in the distribution of care for older adults among provider groups corroborates other Ontario findings. ${ }^{34,49,50}$ NPs were introduced into the Canadian health care system to address the lack of access to services, often for underserved populations. ${ }^{51}$ Although the findings support the view that NPs are providing valuable services to older adults in more rural and remote areas of the province, the geographic variation reinforces ongoing concerns about equity and access to care..$^{50,52}$

Others have pointed out that NPs may not be contributing to primary care as much as they are capable of doing because of misunderstandings about their role or lack of organizational support. ${ }^{37,53}$ The optimal mix of providers and the best models of care that fully use all team members to provide complementary, comprehensive services, without duplication, have yet to be ascertained. Imputing accurate patient-level encounter codes for all health care providers through electronic medical records would assist in quantifying the effect of NP care.$^{37}$ Additionally, provincial administrative databases require better provider indicators to overcome "shadow billing" by NPs that obscure practice activities. ${ }^{37,46,47,53}$

\section{Limitations}

Patient encounters that did not involve a prescription were not captured, resulting in a select patient cohort. Thus, the data do not reflect the full scope of care provided by NPs or FPs to older adults, and the $70 \%$ threshold to assign patients to provider groups is not ideal. Given the restricted formulary for NPs, patient ascertainment before 2011 may have been biased toward physicians. Bias also could have been introduced because we used the first prescription of a study year to identify a patient encounter. We sought to overcome this by tallying each patient's encounters per study year to determine the proportion of care provided. Although we could not determine whether a NP was working specifically in primary care, it is unlikely that patient comorbidity data were skewed is unlikely because we used outpatient data. Finally, although the Corporate Provider Database has been widely used in many provider-level studies at ICES, it has not been validated.

\section{Conclusion}

The NP role was introduced into primary health care teams with provincial support and educational investment, but questions remain about the dispersion of NPs in Ontario's health care system and their impact because of incomplete encounter data. We have described a population of Ontario patients 
aged 65 years and older receiving prescriptions from NPs, providing evidence to optimize the mix of health professional roles in different models of care. More inclusive reporting to provincial databases would enable future work to further determine the impact of NPs and other professionals within the health care team.

\section{References}

1. Patients first: a proposal to strenothen patient-centred health care in Ontario. Toronto: Ontario Ministry of Health and Long-term Care; 2015:1-24. Available: www.health.gov.on.ca/en/news/bulletin/2015/docs/discussion_ paper_20151217.pdf (accessed 2018 Oct. 31).

2. Archibald MM, Fraser K. The potential for nurse practitioners in health care reform. 7 Prof Nurs 2013;29:270-5.

3. Brasset-Latulippe A, Verma J, Mulvale G, et al. Provincial and territorial health system priorities: an environmental scan. Ottawa: Canadian Health Services Research Foundation; 2011. Available: www.cfhi-fcass.ca/SearchResults News/11-12-17/bd8952c0-befd-415b-88d8-fa4e3991d97f.aspx (accessed 2018 Nov. 28).

4. Edwards N, Rowan M, Marck P, et al. Understanding whole systems change in health care: the case of nurse practitioners in Canada. Policy Polit Nurs Pract 2011;12:4-17.

5. What is a nurse practitioner? Toronto: Nurse Practitioners' Association of Ontario (NPAO); 2017. Available: https://npao.org/nurse-practitioners/ overview/ (accessed 2018 Nov. 28).

6. Little L, Reichert C. Fulfilling nurse practitioners' untapped potential in Canada's health care system: results from the CFNU Pan-Canadian Nurse Practitioner Retention \& Recruitment Study. Ottawa: Canadian Federation of Nurses Unions; 2018.

7. Membership statistics report 107. Toronto: College of Nurses of Ontario (CNO); 2018. Available: www.cno.org/en/what-is-cno/nursing-demographics/ statistical-reports/ (accessed 2018 Nov. 28).

8. Regulated nurses, 2014: RN/NP data tables. Ottawa: Canadian Institute for Health Information; 2016. Available: https://www.cihi.ca/en/access-data-reports/ results? query=nurse+practitiones\&Search + Submit $=($ accessed 2018 Oct. 31$)$.

9. NPAO FAQS. Toronto: Nurse Practitioners' Association of Ontario (NPAO); 2019. Available: https://npao.org/about-npao/npao-faqs/ (accessed 2019 Jan. 5).

10. Nurse practitioner-led clinics. Toronto: Nurse Practitioners' Association of Ontario (NPAO); 2019. Available: https://npao.org/about-npao/clinics/ (accessed 2019 Jan. 5).

11. NPAO by the numbers: making healthy change happen [infographic]. Toronto: Nurse Practitioners' Association of Ontario (NPAO); 2018. Available: https:// npao.org/wp-content/uploads/2018/11/npao_infographic_nov4.pdf (accessed 2018 Nov. 28).

12. Chambers LW, West AE. The St. John's randomized trial of the family practice nurse: health outcomes of patients. Int 7 Epidemiol 1978;7:153-61.

13. Spitzer WO, Sackett DL, Sibley JC, et al. The Burlington randomized trial of the nurse practitioner. N Engl 7 Med 1974;290:251-6.

14. Brown SA, Grimes DE. A meta-analysis of nurse practitioners and midwives in primary care. Nurs Res 1995;44:332-9.

15. Horrocks S, Anderson E, Salisbury C. Systematic review of whether nurse practitioners working in primary care can provide equivalent care to doctors. BM7 2002;324:819-23.

16. Way D, Jones L, Baskerville B, et al. Primary health care services provided by nurse practitioners and family physicians in shared practice. CMAF 2001;165:1210-4.

17. Solomon DH, Fraenkel L, Lu B, et al. Comparison of care provided in practices with nurse practitioners and physician assistants versus subspecialist physicians only: a cohort study of rheumatoid arthritis. Arthritis Care Res (Hoboken) 2015;67:1664-70

18. Health Quality Ontario. Specialized nursing practice for chronic disease management in the primary care setting: an evidence-based analysis. Ont Health Technol Assess Ser 2013;13:1-66.

19. Oliver GM, Pennington L, Revelle S, et al. Impact of nurse practitioners on health outcomes of Medicare and Medicaid patients. Nurs Outlook 2014; 62:440-7.

20. Tenuissen DT, Stegeman MM, Bor HH, et al. Treatment by a nurse practitioner in primary care improves the severity and impact of urinary incontinence in women. An observational study. BMC Urol 2015;15: 51.

21. Goldie CL, Prodan-Bhalla N, Mackay M. Nurse practitioners in postoperative cardiac surgery: Are they effective? Can 7 Cardiovasc Nurs 2012; 22:8-15.

22. Hall MH, Esposito RA, Pekmezaris R, et al. Cardiac surgery nurse practitioner home visits prevent coronary artery bypass graft readmissions. Ann Thorac Surg 2014;97:1488-93

23. Peeters MJ, van Zuilen AD, van den Brand JA, et al. Nurse practitioner care improves renal outcome in patients with CKD. 7 Am Soc Nephrol 2014; 25:390-8.
24. Prasad S, Dunn W, Hillier LM, et al. Rural geriatric glue: a nurse practitioner-led model of care for enhancing primary care for frail older adults within an ecosystem approach. 7 Am Geriatr Soc 2014;62:1772-80.

25. Kuo Y-F, Chen N-W, Baillargeon J, et al. Potentially preventable hospitalizations in Medicare patients with diabetes. A comparison of primary care provided by nurse practitioners versus physicians. Med Care 2015;53: 776-83.

26. Borbasi S, Emmaneul E, Farelly B, et al. A nurse practitioner initiated model of service delivery in caring for people with dementia. Contemp Nurse 2010;36:49-60.

27. Bryant-Lukosius D, DiCenso A, Browne G, et al. Advanced practice nursing roles: Development, implementation and evaluation. 7 Adv Nurs 2004; 48:519-29.

28. Donald F, Bryant-Lukosius R, Martin-Misener R, et al. Clinical nurse specialists and nurse practitioners: title confusion and lack of role clarity. Nurs Leadersh (Tor Ont). 2010;23 Spec No 2010:189-210.

29. Kaasalainen SR, Martin-Misener R, Kilpatrick K, et al. A historical overview of the development of the advanced practice nursing roles in Canada. Nurs Leadersh (Tor Ont). 2010; Spec No 2010:35-60.

30. Dahrouge S, Muldoon L, Ward N, et al. The role of nurse practitioners and family physicians in community health centres. Can Fam Physician 2014;60:1020-7

31. Kilpatrick K, Harbman $\mathrm{P}$, Carter N, et al. The acute care nurse practitioner role in Canada. Nurs Leadersh (Tor Ont). 2010;Spec No 2010:114-39.

32. Kilpatrick K, DiCenso A, Bryant-Lukosisus D, et al. How are acute care nurse practitioners enacting their roles in healthcare teams? A descriptive multiple-case study. Int 7 Nurs Stud 2012;49:850-62.

33. Kapu AN, Kleinpell R. Developing nurse practitioner associated metrics for outcomes assessment. 7 Am Assoc Nurse Pract 2013;25:289-96.

34. Tranmer JE, Colley L, Edge DS, et al. Trends in nurse practitioners' prescribing to older adults in Ontario, 2000-2010: a retrospective cohort study. CMAF Open 2015;3:E299-304.

35. Mian O, Lacarte S, Koren I. The NP workforce study: the 2012 survey results. Sudbury $(\mathrm{ON})$ : Centre for Rural and Northern Health Research, Laurentian University; 2012:1-19. Available: http://documents.cranhr.ca/pdf/ CRaNHR_2012_NP_TS_survey_report_November_2012.pdf (accessed 2018 Oct. 31).

36. Strickland S, Woodman M, Moren L, et al. Evaluation of the nurse practitioner access reporting (NPAR) pilot project. Toronto: Ontario Ministry of Health and Long-term Care; 2013. Available: https://npao.org/wp-content/ uploads/2013/12/NPAR-Final-Evaluation-Report-1.pdf (accessed 2018 Nov. 28).

37. Heale R, Dahrouge S, Johnston S, et al. Characteristics of nurse practitioner practice in family health teams in Ontario, Canada. Policy Polit Nurs Pract 2018;19: 72-81.

38. ICES data dictionary. Corporate provider database. Toronto: ICES; 2019. Available: https://datadictionary.ices.on.ca/Applications/DataDictionary/ Default.aspx (accessed 2019 Mar. 11).

39. Ontario's LHINs. Toronto: Local Health Integration Network; 2014. Available: http://www.lhins.on.ca (accessed 2018 Nov. 28).

40. 8. Health system indicators (Canadian Institute for Health Information - CIHI). Cat no 82-221-X. Ottawa: Statistics Canada; 2016. Available: www150.statcan. gc.ca/n1/pub/82-221-x/2013001/quality-qualite/qua8-eng.htm (accessed 2018 Oct. 31).

41. Kralj B. Measuring rurality-RIO2008-BASIC: methodology and results. Toronto: Ontario Medical Association; 2009. Available: www.oma.org/ wp-content/uploads/2008rio-fulltechnicalpaper.pdf (accessed 2018 Nov. 28).

42. Matheson FI, van Ingen T, Maloney G. 2016 Ontario Marginalization Index (ON-Marg). Toronto: Providence St. Joseph's and St. Michael's Healthcare; Joint publication with Public Health Ontario; 2018. Available: www.publichealthontario.ca/en/DataAndAnalytics/Pages/ON-Marg. aspx (accessed 2018 Nov. 28).

43. Elixhauser A, Steiner C, Harris DR, et al. Comorbidity measures for use with administrative data. Med Care 1998;36:8-27.

44. Quan H, Sundararajan V, Halfon $\mathrm{P}$, et al. Coding algorithms for defining comorbidities in ICD-9-CM and ICD-10 administrative data. Med Care 2005;43:1130-9.

45. Jiao S, Murimi, IB, Stafford RS, et al. Quality of prescribing by physicians, nurse practitioners, and physician assistants in the United States. Pharmacotherapy 2018;38:417-27.

46. DesRoches CM, Gaudet J, Perloff J, et al. Using Medicare data to assess nurse practitioner-provided care. Nurs Outlook 2013;61:400-7.

47. Buerhaus PI, DesRoches CM, Dittus R, et al. Practice characteristics of primary care nurse practitioners and physicians. Nurs Outlook 2015;63:144-53.

48. Grumbach K, Hart LG, Mertz E, et al. Who is caring for the underserved? A comparison of primary care physicians and nonphysician clinicians in California and Washington. Ann Fam Med 2003;1:97-104.

49. Green ME, Gozdyra P, Frymire E, et al. Geographic variation in the supply and distribution of comprehensive primary care physicians in Ontario, 2014/15. Toronto: ICES; 2017. Available: www.ices.on.ca/Publications/ Atlases-and-Reports/2017/Geographic-variation-in-physician-supply (accessed 2018 Oct. 31) 
50. Glazier RH, Gozdyra P, Kim M, et al. Geographic variation in primary care need, service use and providers in Ontario, 2015/16. Toronto: ICES; 2018. Available: www.ices.on.ca/Publications/Atlases-and-Reports/2018/ Geographic-Variation-in-Primary-Care (accessed 2018 Oct. 31).

51. Staples E, Ray SL. A historical overview of advanced practice nursing in Canada. In: Staples E, Ray SL, Hannon RA, editors. Canadian perspectives on advanced practice nursing. Toronto: Canadian Scholars Press; 2016:2-22.

52. Income and health. Opportunities to achieve health equity in Ontario. Toronto: Health Quality Ontario; 2016. Available: www.hqontario.ca/ System-Performance/Specialized-Reports/Health-Equity-Report (accessed 2018 Nov. 28).

53. Poghosyan L, Aikin LH. Maximizing nurse practitioners' contributions to primary care through organizational changes. 7 Ambul Care Manage 2015; 38:109-17.

Affiliations: School of Nursing (Edge, Tranmer, VanDenKerkhof) and ICES Queen's (Tranmer, Wei), Queen's University, Kingston, Ont.

Contributors: Dana Edge, Joan Tranmer and Elizabeth VanDenKerkhof contributed to the conception of the research question and design. Dana Edge was responsible for submitting the proposal to ICES and for overseeing the project. Xuejiao Wei conducted the analysis and drafted the methods section of the manuscript; Dana Edge drafted the remainder of the paper. All authors critically appraised the results, revised the manuscript for important intellectual content, provided final approval of the version to be published and agreed to be accountable for all aspects of the work.

Acknowledgement: The authors thank IMS Brogan Inc. for use of their Drug Information Database.

Disclaimer: This study was supported by ICES, which is funded by an annual grant from the Ontario Ministry of Health and Long-Term Care (MOHLTC). The opinions, results and conclusions reported in this article are those of the authors and are independent from the funding sources. No endorsement by ICES or the Ontario MOHLTC is intended or should be inferred. Parts of this article are based on data and/or information compiled and provided by the Canadian Institute for Health Information (CIHI). However, the analyses, conclusions, opinions and statements expressed in the article are those of the authors and not necessarily those of CIHI.

Supplemental information: For reviewer comments and the original submission of this manuscript, please see www.cmajopen.ca/content/7/2/ E323/suppl/DC1. 